Portland State University

PDXScholar

Electrical and Computer Engineering Faculty

Publications and Presentations

$11-10-2016$

\title{
Designing a Continuously Variable Magnetic Gear
}

\author{
J. Pritchard \\ University of North Carolina at Charlotte \\ Pavithra Padmanathan \\ University of North Carolina at Charlotte \\ Jonathan Z. Bird \\ Portland State University, bird@pdx.edu
}

Follow this and additional works at: https://pdxscholar.library.pdx.edu/ece_fac

Part of the Electrical and Computer Engineering Commons

Let us know how access to this document benefits you.

\section{Citation Details}

Pritchard, J.; Padmanathan, Pavithra; and Bird, Jonathan Z., "Designing a Continuously Variable Magnetic Gear" (2016). Electrical and Computer Engineering Faculty Publications and Presentations. 389. https://pdxscholar.library.pdx.edu/ece_fac/389

This Post-Print is brought to you for free and open access. It has been accepted for inclusion in Electrical and Computer Engineering Faculty Publications and Presentations by an authorized administrator of PDXScholar. Please contact us if we can make this document more accessible: pdxscholar@pdx.edu. 


\title{
Designing a Continuously Variable Magnetic Gear
}

\author{
J. Pritchard*, P. Padmanathan* J. Z. Bird ${ }^{*}$, \\ ${ }^{*}$ Electrical and Computer Engineering Department \\ University of North Carolina at Charlotte \\ 9201 University City Boulevard \\ Charlotte, NC, 28223, United States \\ ifpritch@uncc.edu \\ ${ }^{\dagger}$ Laboratory for Electromechanical Energy Conversion and Control \\ Portland State University \\ 1900 SW 4th Avenue, Suite 20-13 \\ Portland, OR, 97201 \\ jonathan.bird@ieee.org
}

Keywords: flux focusing, magnetic gearbox, torque ripple, harmonic analysis.

\begin{abstract}
This paper investigates the performance capabilities of a continuously variable magnetic gearbox that utilizes a flux focusing rotor structure. A fractional slot stator winding is designed to couple to the outer rotor of an existing magnetic gearbox in order to enable the magnetic gearbox to operate with a variable gear ratio.
\end{abstract}

\section{Introduction}

A coaxial magnetic gear (MG) enables speed amplification without mechanical contact. MGs do not require gear lubrication, they have inherent overload protection and they have the potential for quiet operation and high conversion efficiency [1-4]. The flux-focusing coaxial MG, as shown in Figure 1 , consists of an inner rotor with $p_{h}$ pole-pairs, an outer rotor with $p_{c}$ pole-pairs and a central rotor made of $n_{l}$ ferromagnetic segments. The governing equation for a coaxial $\mathrm{MG}$ is [1]

$$
\omega_{h} p_{h}=n_{l} \omega_{l}-p_{c} \omega_{c}
$$

where $\omega_{h}=$ high-speed angular velocity (on rotor 1 ), $\omega_{l}=$ low-speed angular velocity (on rotor 2) and $\omega_{c}$ is often stationary $\left(\omega_{c}=0\right.$ on rotor 3$)$. Shah [5] demonstrated that if the input speed varies the output speed can be made constant using a separate external motor to drive the outer rotor. This results in a continuously variable magnetic gear (CVMG) with a gear ratio given by:

$$
G_{r}=\frac{\omega_{h}}{\omega_{l}}=\frac{n_{l}}{p_{h}}-\frac{p_{c}}{p_{h}} \frac{\omega_{c}}{\omega_{l}}
$$

when $\omega_{c}=0, G_{r}=n_{l} / p_{h}$, which is the nominal gear ratio. Jian demonstrated that the same type of CVMG can be created using an outer control rotor stator [6]. Using finite element analysis (FEA), Jian simulated the performance of a 2.6:1 nominal gear ratio CVMG that used a dual Halbach rotor structure. The calculated torque and torque density were reported to be $816 \mathrm{Nm}$ and $136.6 \mathrm{Nm} / \mathrm{L}$ respectively, but there were no experimental results to validate the calculations.

Atallah designed and tested an experimental CVMG with a 1.23:1 nominal gear ratio using a stator that interacted with an outer control rotor $[7,8]$. Using FEA, Atallah calculated a torque density of $37.8 \mathrm{Nm} / \mathrm{L}$, while the measured torque density of the experimental CVMG was $26.4 \mathrm{Nm} / \mathrm{L}$ [8].

Zaini [9] and Padmanathan [10] demonstrated that a CVMG could also be created by replacing the outer rotor with a stator. However, as the stator provides a significant portion of the magnetizing flux the torque density is inherently low $[11,12]$, with Zaini reporting a torque density of $13.2 \mathrm{Nm} / \mathrm{L}$. The use of the stator to magnetize the MG also significantly lowers the power factor and creates a large torque ripple [11].

In this paper a 4.25:1 nominal gear ratio CVMG with a flux focusing control rotor is investigated. The design is shown in Figure 2. Unlike other proposed topologies [6-8] the outer MG rotor, called the control rotor in this paper, shares the magnetic flux with both the stator and the inner MG rotors. As the stator interacts with the outer rotor, rather than the inner rotor, as in $[7,8]$ the stator torque production is more directly connected. However the disadvantage of this approach is that the required stator torque will be higher than what is needed to interact with the higher speed inner rotor.

If a CVMG can be shown to operate at high torque, relative to both the overall size and the weight of the magnets used, then it could have significant practical potential, particularly for hybrid electric vehicles [6,8] as well as wind [8,9] and marine hydrokinetic power generation [13]

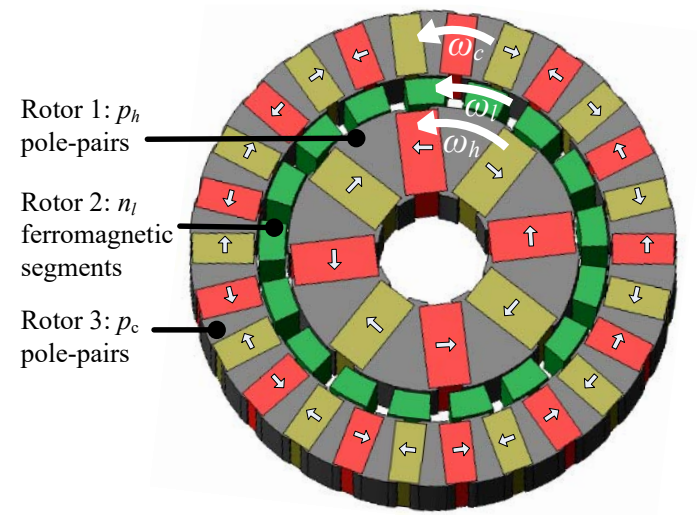

Figure $1 \mathrm{~A}$ coaxial magnetic gear using a flux focusing rotor topology with $p_{h}=4$ pole-pairs on the inner high-speed rotor, $n_{l}=17$ steel poles on the low-speed rotor and $p_{c}=13$ pole-pairs on the outer rotor [4]. 


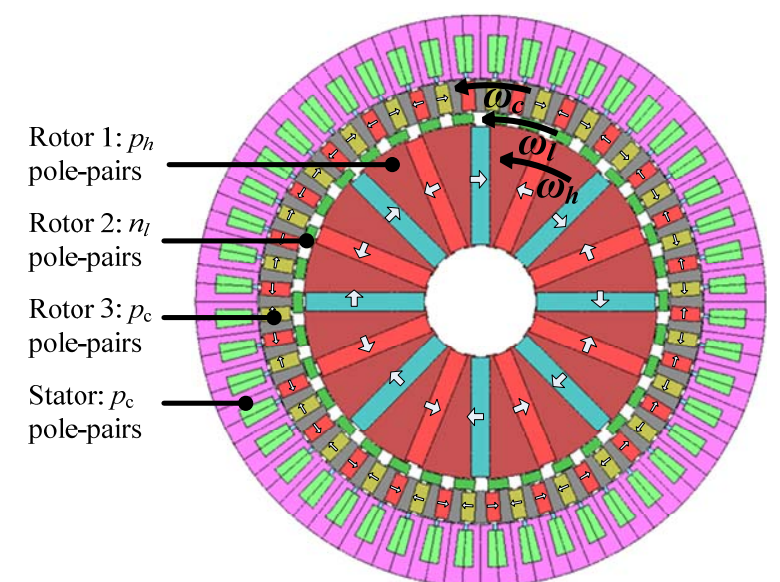

Figure 2: A flux focusing continuously variable magnetic gear with $p_{h}=8$ pole-pairs on the inner high-speed rotor, $n_{l}=34$ steel modulation poles on the low-speed rotor and $p_{c}=26$ pole-pairs on the outer control rotor. Arrows indicate magnetization direction.

\section{Continuously Variable Magnetic Gear}

The dominant radial field component created by the highspeed rotor (rotor 1) can be approximated by assuming that it is given by:

$$
B_{r}^{h}(r, \theta, t)=b_{r}^{h}(r) \sin \left[p_{h}\left(\theta-\omega_{h} t\right)+p_{h} \theta_{h}\right]
$$

where $\theta_{h}$ is the initial mechanical angular position of rotor 1 . The ferromagnetic poles on rotor 2 create a radial modulating pattern with a dominant harmonic given as:

$$
\Gamma_{r}^{l}(r, \theta, t)=\lambda_{r}^{l}(r) \sin \left[n_{l}\left(\theta-\omega_{l} t\right)+n_{l} \theta_{l}\right]
$$

where $\theta_{l}$ is the initial mechanical angular position of rotor 2 . The high-speed rotor's field modulated by rotor 2 gives a field in the outer rotor air-gap (at $r=r_{c}$ ) of:

$$
B_{r}^{c}\left(r_{c}, \theta, t\right)=\Gamma_{r}^{l}\left(r_{c}, \theta, t\right) B_{r}^{h}\left(r_{c}, \theta, t\right)
$$

Substituting (3) and (4) into (5) and then using a trigonometric identity one obtains:

$$
\begin{gathered}
B_{r}^{c}(r, \theta, t)=B_{o}^{c}\left(\cos \left[\left(n_{l}-p_{h}\right)\left(\theta-\frac{n_{l} \omega_{l}-p_{h} \omega_{h}}{n_{l}-p_{h}} t\right)+n_{l} \theta_{l}-p_{h} \theta_{h}\right]\right. \\
\left.-\cos \left[\left(n_{l}+p_{h}\right)\left(\theta-\frac{n_{l} \omega_{l}+p_{h} \omega_{h}}{n_{l}+p_{h}} t\right)+n_{l} \theta_{l}+p_{h} \theta_{h}\right]\right)
\end{gathered}
$$

where $B_{o}^{c}=b_{r}^{h}\left(r_{c}\right) \lambda_{r}^{l}\left(r_{c}\right) / 2$.

Assuming linearity, the torque in the control rotor's inner airgap is [14]:

$$
T=\frac{2 d r_{c}^{2}}{\mu_{0}} \int_{0}^{2 \pi} B_{r}^{c}\left(r_{c}, \theta, t\right) B_{\theta}^{c}\left(r_{c}, \theta, t\right) d \theta
$$

where:

$$
B_{\theta}^{c}\left(r_{c}, \theta, t\right)=b_{\theta}^{c}\left(r_{c}\right) \sin \left[p_{c}\left(\theta-\omega_{c} t\right)+p_{c} \theta_{c}\right]
$$

is the dominant component of the radial flux density created by the outer (control) rotor and $d$ is the axial length of the
CVMG. The integration of the two field functions in (7) will result in a non-zero torque only when

$$
p_{c}=n_{l} \pm p_{h} \text {. }
$$

The CVMG under study in this paper has $\left(p_{h}, p_{c}, n_{l}\right)=(8,26,34)$. Therefore

$$
p_{c}=n_{l}-p_{h}
$$

and so the first term in (6) applies. Given (10), for non-zero steady-state torque one must also have [15]:

$$
\omega_{c}=\frac{n_{l} \omega_{l}-p_{h} \omega_{h}}{n_{l}-p_{h}}
$$

with (11) the steady-state torque from (7) becomes:

$$
T_{c}=T_{o} \sin \left(p_{h} \theta_{h}+p_{c} \theta_{c}-n_{l} \theta_{l}\right)
$$

where $T_{o}=\frac{2 d r_{c}^{2} \pi}{\mu_{0}} b_{\theta}^{c}\left(r_{c}\right) b_{r}^{h}\left(r_{c}\right) \lambda_{r}^{l}\left(r_{c}\right)$

is the peak torque. Substituting (10) into (11) yields (1). With $\left(p_{h}, p_{c}, n_{l}\right)=(8,26,34)$ the speed relationship in (1) is:

$$
\omega_{h}=4.25 \omega_{l}-3.25 \omega_{c}
$$

As the stator electrical frequency, $\omega_{e}$, and mechanical angular velocity, $\omega_{c}$, are related by:

$$
\omega_{c}=\omega_{e} / p_{c}
$$

then (14) becomes:

$$
\omega_{h}=4.25 \omega_{l}-0.125 \omega_{e}
$$

Figure 3 shows geometric parameter definitions Table 1 gives the geometric parameter values, while Figure 4 shows the inner magnetic gear (MG) assembly and Figure 5 shows the assembled MG. In this paper only the stator design is being considered. The purpose of this paper is to present a stator design that can fit over a MG to enable the MG to act as a CVMG. Unlike in [16] the outer rotor, called a control rotor in this paper, is allowed to rotate and therefore will interact with both the stator winding and low speed rotor. The control rotor has $p_{c}=26$ pole-pairs and therefore a fractional slot stator winding [17], with 4/13 slots-per-pole-per-phase, has been selected so as to enable a large number of poles to be accommodated within a small relative diameter $(0.226 \mathrm{~m})$.

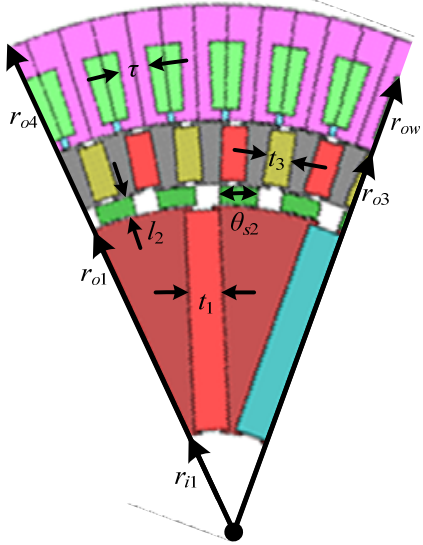

Figure 3: Definition of the geometric parameters 


\begin{tabular}{|c|c|c|c|}
\hline \multicolumn{2}{|l|}{ Description } & Value & Unit \\
\hline \multirow{5}{*}{$\begin{array}{l}\text { Inner rotor } \\
\text { (high speed) }\end{array}$} & Pole pairs, $p_{h}$ & 8 & - \\
\hline & Inner radius, $r_{i 1}$ & 28 & $\mathrm{~mm}$ \\
\hline & Outer radius, $r_{o 1}$ & 90 & $\mathrm{~mm}$ \\
\hline & Magnet thickness, $t_{1}$ & 9.5 & $\mathrm{~mm}$ \\
\hline & Airgap, $g$ & 0.5 & $\mathrm{~mm}$ \\
\hline \multirow{3}{*}{$\begin{array}{l}\text { Cage rotor } \\
\text { (low speed) }\end{array}$} & Steel poles, $n_{l}$ & 34 & - \\
\hline & Cage bar radial thickness, $l_{2}$ & 5 & $\mathrm{~mm}$ \\
\hline & Pole span, $\theta_{s 2}$ & $180 / p_{3}$ & degrees \\
\hline \multirow{5}{*}{ Control rotor } & Pole pairs, $p_{c}$ & 26 & - \\
\hline & Inner radius, $r_{i 3}$ & 96 & $\mathrm{~mm}$ \\
\hline & Outer radius, $r_{o 3}$ & 113 & $\mathrm{~mm}$ \\
\hline & Magnet thickness, $t_{3}$ & 7 & $\mathrm{~mm}$ \\
\hline & Airgap, $g$ & 0.5 & $\mathrm{~mm}$ \\
\hline \multirow{6}{*}{ Stator } & Number of slots & 48 & - \\
\hline & Tooth width, $\tau$ & 8 & $\mathrm{~mm}$ \\
\hline & Outer radius, $r_{o 4}$ & 145 & $\mathrm{~mm}$ \\
\hline & slot inner radius $r_{i 4}$ & 113.5 & $\mathrm{~mm}$ \\
\hline & slot outer radius, $r_{o w}$ & 135 & $\mathrm{~mm}$ \\
\hline & Winding fill factor & 60 & $\%$ \\
\hline \multirow{2}{*}{ Material } & $\mathrm{NdFeB}$ magnet, $\mathrm{N} 40 \mathrm{H}, B_{r}$ & $1.25 \mathrm{~T}$ & $\mathrm{~T}$ \\
\hline & Stator lamination steel (JFE, 35JN270) & - & - \\
\hline \multicolumn{2}{|c|}{ Active region stack length, $d$} & 75 & $\mathrm{~mm}$ \\
\hline
\end{tabular}

Table 1: Geometric and Material Parameters

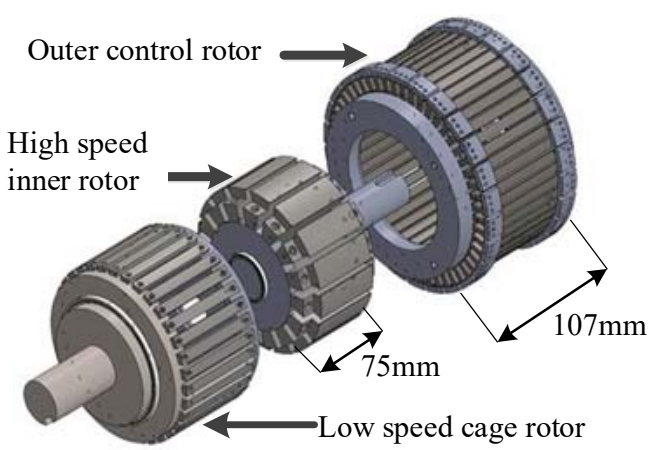

Figure 4: Exploded view of the magnetic gear mechanical assembly [16]

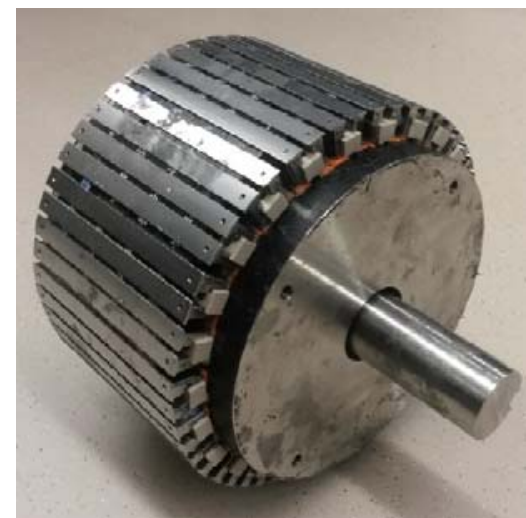

Figure 5: Fully assembled inner magnetic gear with outer control rotor shown [16]

The control rotor speed, $\omega_{c}$, is a function of the input speed, $\omega_{l}$, and the desired output speed, $\omega_{h}$. When the speeds are constant the net torque on the control rotor, $T_{c}$, must be zero. The torque applied by the stator must be balanced by the torque from the MG cage rotor. A non-zero net torque can only exist during acceleration or deceleration. Therefore at steady-state the torque must satisfy

$$
T_{h}+T_{l}+T_{s}=0
$$

where $T_{h}=$ high-speed rotor torque, $T_{l}=$ low-speed rotor torque and $T_{s}=$ stator torque.

\section{Stator Harmonic Analysis}

The harmonics created by the fractional slot stator winding can be investigated by computing the harmonic components. Considering the winding function [18] pattern for fractional slot phase-A winding as shown in Figure 6 the corresponding winding function for phase-A can be sketched as shown in Figure 7. The Fourier series that reproduces Figure 7 is then:

$$
n(\theta)=\sum_{k=1}^{\infty} b_{k} \sin (k \theta)
$$

where

$$
\begin{aligned}
& b_{k}=\frac{N}{\pi k}\left[\cos \left(k \frac{9 \pi}{24}\right)-\cos \left(k \frac{11 \pi}{24}\right)+\cos \left(k \frac{13 \pi}{24}\right)-\cos \left(k \frac{15 \pi}{24}\right)\right. \\
& +\cos \left(k \frac{35 \pi}{24}\right)-\cos \left(k \frac{33 \pi}{24}\right)+\cos \left(k \frac{39 \pi}{24}\right)-\cos \left(k \frac{37 \pi}{24}\right) \text { (19) }
\end{aligned}
$$

A plot of the winding function (18) for phase-A and the resulting 3-phase winding function is shown in Figure 8.

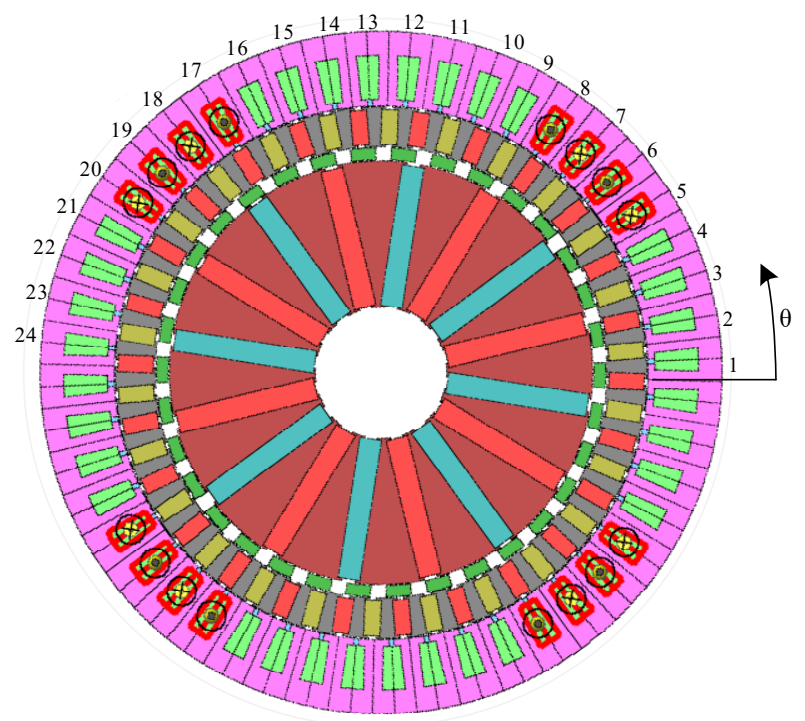

Figure 6: 48 slot stator with phase-A concentrated winding layout shown. The first 24 slot numbers are shown.

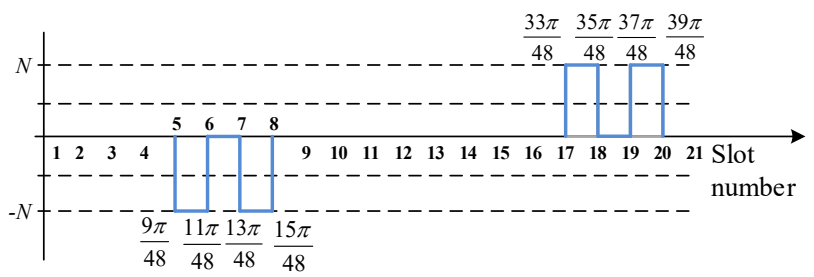

Figure 7: Winding function with corresponding slot number and angular position shown. 


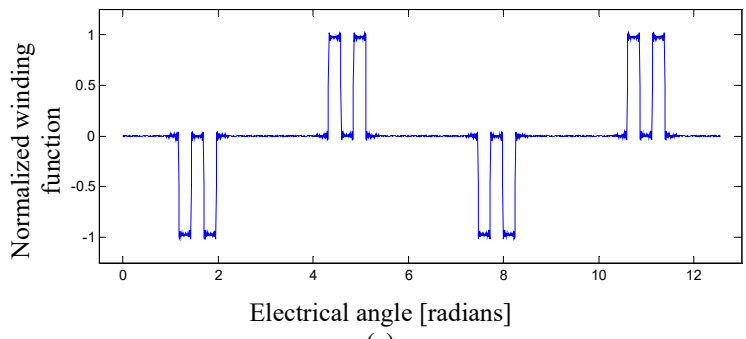

(a)

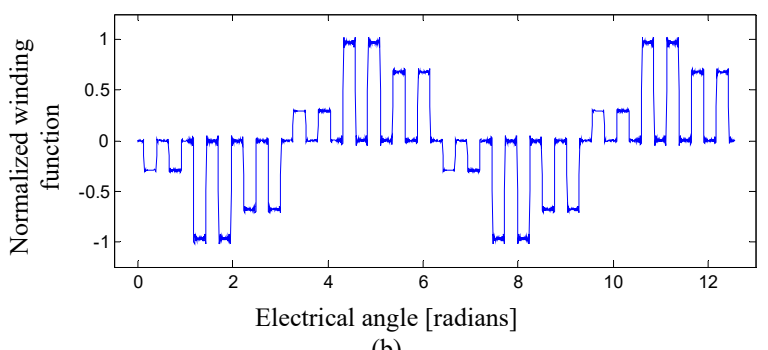

(b)

Figure 8: (a) Winding function Fourier series representation of phase A and (b) winding function for all three phases.

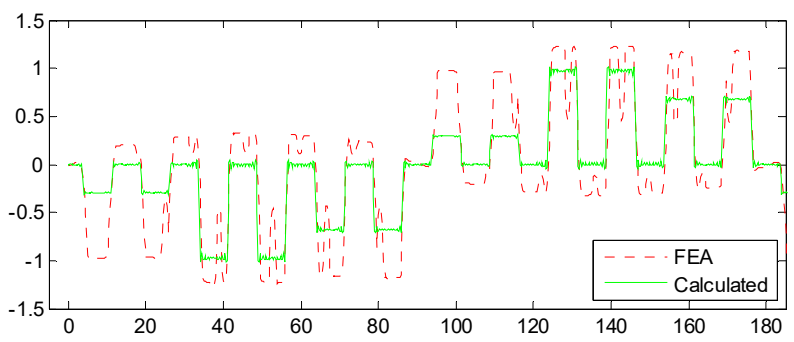

Figure 9: Overlay of analytic winding function values with the calculated magnetic flux density values [T]. The analytic values were normalized.

The harmonics created by the winding function should follow that created by the air-gap field [18]. Figure 9 compares the winding function with the radial field components computed using JMAG finite element analysis (FEA) software. FEA field values were calculated by changing the control rotor magnets to steel. This prevented any external MG harmonics from being created. Figure 9 shows that the field magnitudes are different, however the simple winding function analysis technique accurately determines the field profile. A comparison of the harmonic components calculated from the FEA and analytic model is given in Figure 10. Figure 10 confirms that the analytic model accurately predicts the presences of the relevant spatial components. A $26^{\text {th }}$ harmonic component is indeed created and this is the major torque producing component.

Using the geometric and material values shown in Table 1 and electrical and mechanical values shown in Table 2 a set of magnetostatic simulations were used to calculate the torque under peak load. It was determined that the control rotor torque will go to zero when a stator current density of $J=17 \mathrm{~A} / \mathrm{mm}^{2}$ is used. A transient and magnetostatic simulation was used to confirm these results and the torque values are shown in Table 3 . The transient results show significant torque ripple. This torque ripple is not seen in simulations without stator excitation [16], which points to the stator flux harmonics as the cause.

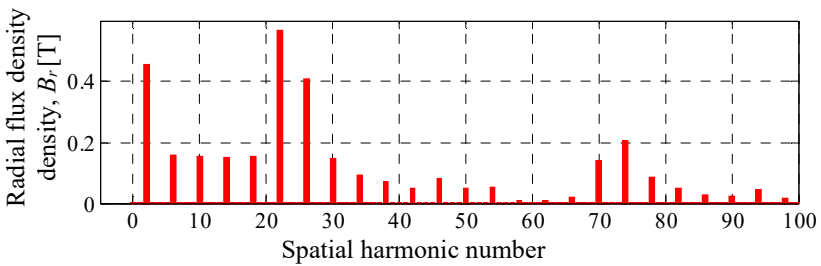

(a)

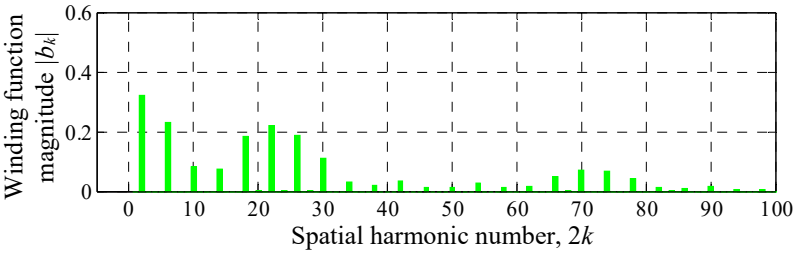

(b)

Figure 10: (a) Radial harmonic flux density calculated using FEA and (b) winding function harmonic components. The winding function analysis accuracy predicts the relevant harmonics.

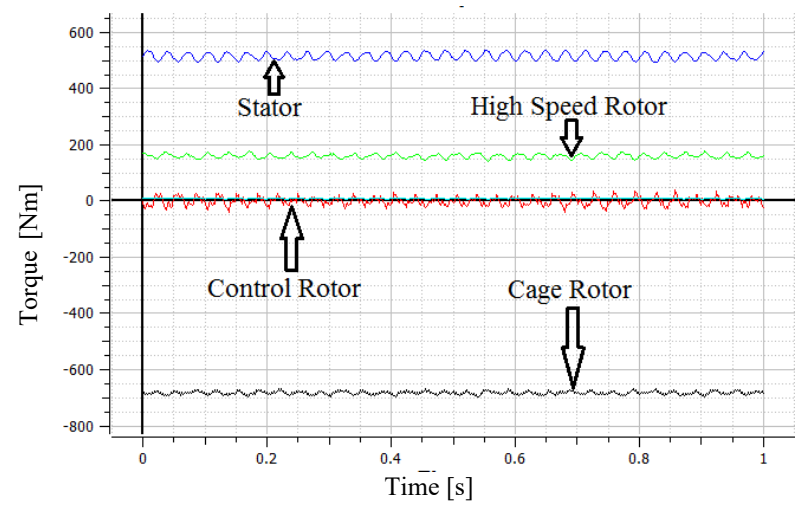

Figure 11: Transient torque analysis when the control rotor torque is made zero

\begin{tabular}{|l|l|l|}
\hline Description & Value & Unit \\
\hline Current amplitude, $J$ & 17 & $\mathrm{~A} / \mathrm{mm}^{2}$ \\
\hline Current frequency, $f_{\mathrm{e}}$ & 5.2 & $\mathrm{~Hz}$ \\
\hline Initial electrical angle, $\theta_{e}$ & 25.3 & degrees \\
\hline High speed rotor speed, $\omega_{\mathrm{h}}$ & 73 & $\mathrm{rpm}$ \\
\hline Cage rotor speed, $\omega_{l}$ & 8 & $\mathrm{rpm}$ \\
\hline Control rotor speed, $\omega_{\mathrm{c}}$ & -12 & $\mathrm{rpm}$ \\
\hline
\end{tabular}

Table 2: Transient simulation conditions that gives zero control rotor torque.

\begin{tabular}{|l|c|c|c|}
\hline Component & $\begin{array}{c}\text { Static } \\
{[\mathrm{Nm}]}\end{array}$ & $\begin{array}{c}\text { Transient (Avg) } \\
{[\mathrm{Nm}]}\end{array}$ & $\begin{array}{c}\text { Ripple } \\
{[\mathrm{Nm}]}\end{array}$ \\
\hline High speed rotor & 166.3 & 160.5 & 21.4 \\
\hline Low speed (cage) rotor & -683.9 & -682.1 & 22.2 \\
\hline Control rotor & -2.0 & -0.37 & 57.0 \\
\hline Stator & 521.2 & 525.2 & 33.4 \\
\hline
\end{tabular}

Table 3: Magnetostatic and transient torque calculations 


\section{Stator Design}

As a current density of $J=17 \mathrm{~A} / \mathrm{mm}^{2}$ would be too high for continuous operation, when air-cooled, a parameter study was conducted in order to maximize the stator torque capability. The stator tooth width, $\tau$, and coil outer radius, $r_{o w}$, were both varied while keeping the current density constant at $J=8$ $\mathrm{A} / \mathrm{mm}^{2}$. The resulting stator and control rotor torques are shown in Figure 12. Figure 12(a) shows that the stator torque is maximum at $\tau=9.5 \mathrm{~mm}$. Further increases in tooth width lead to a reduction in torque. This is likely caused by flux leakage between the control rotor permanent magnets through the ends of the wider stator teeth. Further increases in the stator slot outer radius had only an incremental effect on torque, due to saturation. Figure 12(b) shows that the control rotor torque will not reduce to zero when using a $J=8 \mathrm{~A} / \mathrm{mm}^{2}$ current density. At $r_{\text {ow }}=180 \mathrm{~mm}$ the control rotor torque is still at $T_{c}=28.8 \mathrm{Nm}$. There is little improvement obtained by increasing $r_{o w}$ further. This analysis shows that this final stator design will be too large to be constructed and will not be able to meet the peak torque operating condition of the MG (since $\left.T_{c} \neq 0\right)$.

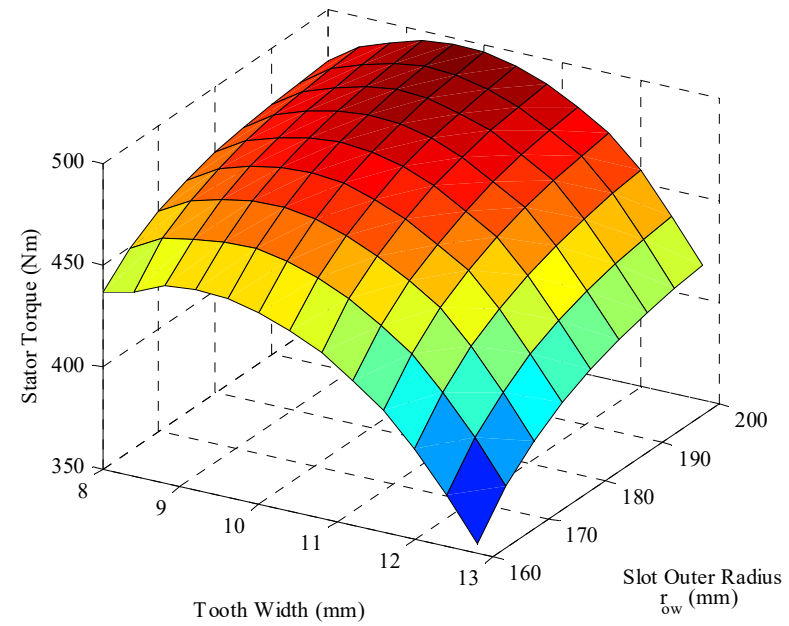

(a)

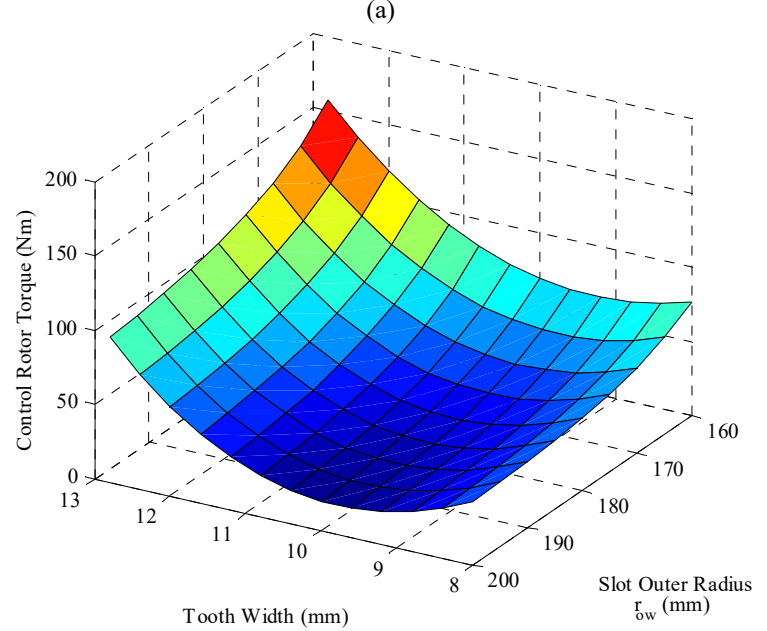

Figure 12: (a) Stator torque and (b) control rotor torque as a function of stator tooth width, $\tau$, and stator slot outer radius, $r_{\text {ow }}$.
Until this point, the effective stack length of the three rotors and the stator were all assumed to be $d=75 \mathrm{~mm}$. However in order to mechanically embed the inner rotors the outer control rotor axial length was mechanically made longer and therefore the active region of the outer rotor can accommodate additional magnets thereby enabling the outer rotor to have an axial active length of $d_{s}=107 \mathrm{~mm}$ (refer Figure 4). As the inner rotor only has a $75 \mathrm{~mm}$ axial active region not all of the inner rotor magnets will therefore interact with the outer control rotor magnets. If the outer stator is now designed to have a $107 \mathrm{~mm}$ axial length it will enable a higher torque to be attained on the control rotor without significantly increasing the mechanical size of the CVMG.

The performance when using a $d=75 \mathrm{~mm}$ axial inner rotor length and a $d_{s}=107 \mathrm{~mm}$ control rotor and stator axial length was investigated by using a 2-D simulation in which the axial length of the MG was set to $107 \mathrm{~mm}$ and then the relative phase angle of the cage rotor torque was adjusted to reduce the $\mathrm{MG}$ torque down to $70 \%$ of peak value $(75 / 107=0.7)$. An earlier trial had showed that increasing the magnets in one rotor alone had little effect on the maximum torque produced by the MG. Using this approach the torque analysis values shown in Table 4 were obtained when using a current density of $J=5 \mathrm{~A} / \mathrm{mm}^{2}$. The cage rotor torque is computed to be $677 \mathrm{Nm}$ and the control rotor torque is close to zero. This indicates that this design approach can lead to a higher torque operation at lower current density.

\begin{tabular}{|l|c|c|}
\hline Component & Torque $[\mathrm{Nm}]$ & Torque ripple $[\mathrm{Nm}]$ \\
\hline Low speed cage rotor & -677.1 & 28.7 \\
\hline Control rotor & -18.6 & 66.0 \\
\hline High speed rotor & 158.9 & 29.0 \\
\hline Stator & 539.5 & 35.7 \\
\hline
\end{tabular}

Table 4: Torque and torque ripple values for $d_{s}=107 \mathrm{~mm}$ axial stator length and $J=5 \mathrm{~A} / \mathrm{mm}^{2}$ current density.

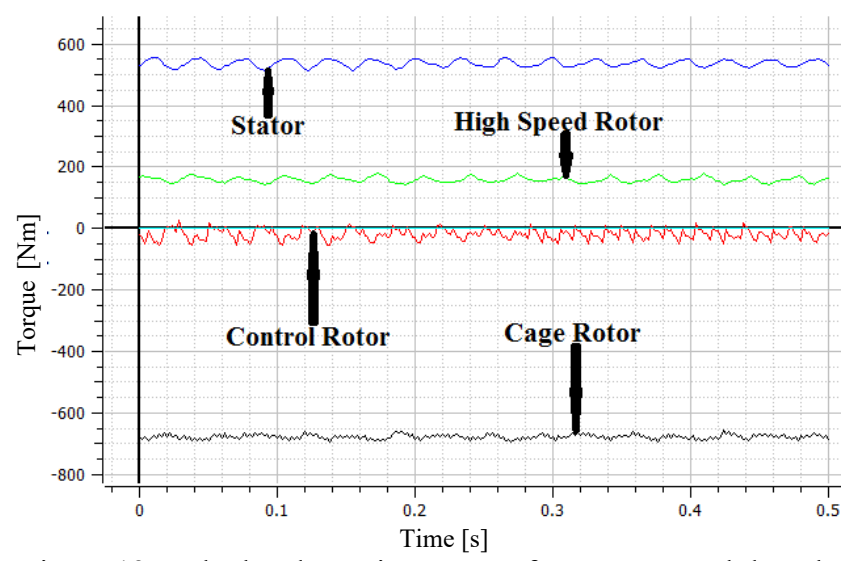

Figure 13: Calculated transient torque for a stator stack length of $d_{s}=107 \mathrm{~mm}$ and $\left(r_{o w}, r_{o 4}\right)=(165,175) \mathrm{mm}$ and $J=5 \mathrm{~A} / \mathrm{mm}^{2}$. 


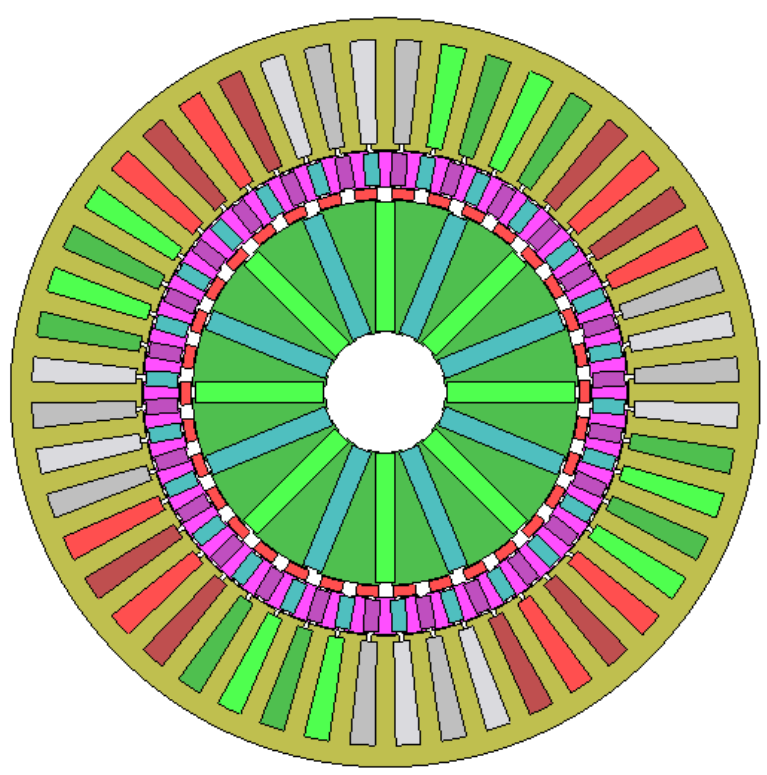

Figure 14: 2-D FEA model of the continuously variable magnetic gearbox with $\left(r_{o w}, r_{o 4}\right)=(165,175) \mathrm{mm}$

\section{Conclusions}

The initial design analysis of a flux focusing CVMG has been presented. The design differs from previous CVMG designs in that the outer rotor of the MG is used to both couple with the stator and the low-speed MG rotor. However, using this approach creates a number of challenges. In particular, the harmonics created by the stator must be carefully assessed in order to ensure that they do not create large torque ripples in the MG. Furthermore, by controlling the outer rotor of the MG the stator torque requirements are more challenging. In order to meet the MG torque requirements the active region axial length of the outer rotor of the MG and stator had to be increased.

\section{Acknowledgment}

The authors would gratefully like to thank the JMAG Corporation for the use of their FEA software. This material is based upon work supported by the North Carolina Coastal Studies Institute and the National Science Foundation under Grant No. 1408310.

\section{References}

[1] T. B. Martin, "Magnetic Transmission," USA Patent 3,378,710, 1968.

[2] P. O. Rasmussen, T. O. Andersen, F. T. Jorgensen, and $O$. Nielsen, "Development of a highperformance magnetic gear," IEEE Trans. Ind. Appl., vol. 41, pp. 764-770, 2005.

[3] K. Atallah, S. D. Calverley, and D. Howe, "Design, analysis and realisation of a high-performance magnetic gear," IEE Proc.-Electr. Power Appl., vol. 151, pp. 135-143, 2004.
[4] K. K. Uppalapati, W. Bomela, J. Bird, M. Calvin, and J. Wright, "Experimental Evaluation of Low Speed Flux Focusing Magnetic Gearboxes," IEEE Trans. on Ind. Appl., vol. 50, pp. pp. 3637 - 3643, Nov/Dec 2014.

[5] L. Shah, A. Cruden, and B. W. Williams, "A variable speed magnetic gear box using contrarotating input shafts," IEEE Trans. Mag., vol. 47, pp. 431-438, 2011.

[6] L. Jian and K. T. Chau, "Design and analysis of a magnetic-geared electronic-continuously variable transmission system using finite element method," Progr. Electrmagn. Res., vol. 107, pp. 47-61, 2010.

[7] J. Wang, K. Atallah, and S. D. Carvley, "A magnetic contionously variable transmission device," IEEE Trans. Mag., vol. 47, pp. 2815-2818, 2011.

[8] K. Atallah, J. Wang, S. D. Calverley, and S. Duggan, "Design and Operation of a magnetic continously variable transmission," IEEE Trans. Ind. Appl., vol. 48, pp. 1288-1295, 2012.

[9] A. Zaini, N. Niguchi, and K. Hirata, "Continously variable speed vernier magnetic gear," IEEE Trans. Mag., vol. 48, pp. 3104-3107, Nov. 2012.

[10] P. Padmanathan and J. Z. Bird, "A continuously variable magnetic gear," in Electric Machines \& Drives Conference (IEMDC), 2013 IEEE International, 2013, pp. 367-373.

[11] P. Padmanathan, "Design of a continuously variable magnetic gear," M.S. Thesis, Elect. and Comp. Eng., Univ. North Carolina at Charlotte, Charlotte, USA, Dec. 2013.

[12] M.Johnson, A.Shapoury, H. A. Toliyat, P. Boghrat, and M. Post, "Review of magnetically geared motors and analysis of their potential for naval propulsion applications," presented at the Electric Machines Technology Symposium (EMTS) 2014, Villanova, PA, 2014.

[13] J. Bird, "Marine hydrokinetic power take-off using magnetic gearing," presented at the 2nd Marine Energy Technology Symposium, Seattle, WA, 2014.

[14] J. Bird, "A Decoupled Quasi-Static Stress Tensor Formulation," presented at the Advances in Magnetic Conference, Bormio, Italy, 2016.

[15] K. Atallah and D.Howe, "A Novel HighPerformance Magnetic Gear," IEEE Trans. on Magn. , vol. 37, pp. 2844 - 28462001.

[16] K. K. Uppalapati, J. Z. Bird, J. Wright, J. Pitchard, M. Calvin, and W. Williams, "A magnetic gearbox with an active region torque density of $239 \mathrm{Nm} / \mathrm{L}$," in IEEE Energy Conv. Cong. Expo., 2014, pp. 14221428.

[17] P. Salminen, "Fractional Slot Permanent Magnet Synchronous Motors for Low Speed Applications," Ph.D. Thesis, Lappeenranta University of Technology, Lappeenranta, Finland, 2004.

[18] N. L. Schmitz and D. W. Novotny, Introductory Electromechanics: Ronald Press Co., 1965. 